Irada Y. Alakbarova

DOI: $10.25045 /$ jpis.v07.i1.09

ANAS Institute of Information Technology, Baku, Azerbaijan

airada.09@gmail.com

\title{
WIKIPEDIA ENCYCLOPEDIA AS A MANIPULATIVE TOOL IN SOCIAL MEDIA
}

The analysis of secured management technologies has become one of the factors of information security in the modern information society. The use of Wiki-projects as one of the social media tools in information impact is closely related to the wide application of informationcommunication instruments. The primary aim of the research is to study the social media phenomenon, the stance of wiki-environment as one of the social media tools in the society and its role in information impact. For this purpose, the notion of social media is explored and the fields encompassed by social media are specified. The problems associated with user content in wikienvironment are indicated and the essence of Creative Commons license is clarified. The main tendencies providing the information impact of wiki-environment are determined in the article.

Key words: social media, social network, blog, wiki-environment, information impact, podcast, user content, Creative Commons.

\section{Introduction}

Nowadays, millions of Internet users from various parts of the world devote their time, experience and knowledge to various projects of virtual space: the creation of social media contents in social networks, blogs, forums, open encyclopedias and websites. Different news programs, knowledge sources, blog articles, tweets, virtual study materials and images, video and audio materials, in different formats, are attributed to this content. Modern informationcommunication technologies (ICT) are playing a prominent role in the development of social media, as in different fields of the society. The wide opportunities of the Internet, in particular confirms once again that it is not only the information and communication environment, but also a new reality of our everyday life and a field of activity of many people. It is to be considered that no customs and boundary control exist for information. People from different continents can freely communicate here. As a result, several new interests, goals, needs, activities, also the forms of psychological and social activity of Internet users emerge in association with the global network [1].

The Internet capabilities have facilitated the emergence of the gigantic information resources such as social media. The social media - creates the opportunity to establish social communication among people and share various information via the

The Internet tools. By using more accessible and web-based technologies, it turns the communication to an interactive dialogue, rapid dissemination of information in the society and the mirror of reactions of people to various events and processes. Information web-sites broadcasted via the Internet, social networks, blogs, microblogs, wiki-projects, instant communication programs, and forums pertain to social media tools [2].

Social media plays a prominent role in formation of information society. Hence, the essential philosophy of the information society is expressed as the satisfaction of people's need for information and knowledge, regardless the age, language, religion, social and political affiliation, education and occupation; the creation of social communication environment among those, and communicating any information to community. [3]. These opportunities are acquired through the direct use of web 2.0 and 3.0 program products and wiki technologies. The networks pertaining to social media facilitate the establishment of unofficial communication between the user and the experts of different fields. Thus, in social media, people are more open and active, and eager to share knowledge more than in real life [2,4]. Facebook and Twitter social networks, Wikipedia virtual encyclopedia can be shown as an example. Unlike the traditional web pages, users do not only obtain particular information passively, but also participate in generating and 
editing information in projects representing the social media. The social media, as an addition to traditional media tools, facilitates the collection of useful information and information exchange among people, and plays a central role in satisfaction of information requirements and acquirement of additional knowledge in the process of scientific research.

The social media is transforming the people, their lifestyle, worldviews, communication tools and habits. The social media has a key role in globalization of the world by eliminating the boundaries among the states and people. The social activity of citizens in global network poses the tasks such as the strengthening control over social media, the monitoring, the use of social media tools in own purposes alongside the protection of information space of a state. The social media that emerged with the impact of Web 2.0 technologies has yielded expansion of other social activity fields. This, in turn, actualizes the issues of investigation of social media's role in information impact on society [5]. Wiki-environment as one of the main tools of social media plays an important role in information impact today. The reason for this is the extremely large information and reader audience of wiki-projects, and the its recognition as an easily accessible and reliable knowledge source in the society [6].

\section{The fields of social media}

Social media attracts more experienced, educated and serious users day by day. Social media is also affecting the economic, political and cultural relations [6,7]. People trust in social media and attempt to analyze the events occurring in the society with the help of social media. The social media can be encountered in most projects of the Internet today $[4,8]$.

The fields encompassed by the social media are as following:

- social networks;

- blogs;

- wiki projects;

- forums,

- content sharing;

- podcasts;

- microblogs;

Social media is a group consisting of social structural links between social mutual relations, social objects (people and organizations) and communications. The social network, in the Internet environment, is referref to interactive and multi-user web-site, in which people with common interests gather together. In this web-site, as an automatized social environment, the information is posted by the Internet users, who are assembled in a particular group. Social networks are gigantic information resources: vast amount of information related to people, events, products and organizations is inserted in different languages of the world. Social network is a favorable place for the promotion of a particular idea and thought $[8,9]$.

Social networks support the virtual activities such as the collection of important information, the transmission of various information (information protected by copyright rights, personal information, misinformation, false information, spam), promulgation and validation of particular ideas, and income earning using network acquaintance. MySpace, Facebook and LinkedIn social networks are more popular among young people. Nexopia, Hi5, Tagged, XING, Skyrock, Orkut, Friendster, Multiply, Xiaonei and Cyworld projects can be shown as other popular social networks.

Blog is the best-known type of social media. Being an Internet-diary, blogs are wide information sources regarding the socio-economic, political and other events occurring in the world. At the same time, a blog is a virtual society gathering people around a particular topic. Blogs can be personal and professional. Personal blogs are more widely spread. In such blogs, a blogger shares his/her observations and thoughts with readers, writes about the issues, in which he/she is concerned, and tries to engage readers in discussions. Expert blogs differ from personal 
blogs in the method of introducing the information. In such blogs, a blogger introduces him/herself as an expert and attempts to shape an opinion of readers in a particular topic. Corporate blogs occupy a larger space among expert blogs. Corporate blog is created and managed by a company. By this type of blogs, a company tries to introduce itself as an institution benefiting the society, and to increase the number of supporters. Journalist blogs also occupy a special place among expert blogs. In a modern age of the development of information society, it is impossible to imagine a professional journalist without a personal blog. For a journalist, a blog is a tool for increasing the prestige, trustworthiness and professionalism. Such blogs are often considered as mass media blogs. Blogger, WordPress and other respective projects can be shown as an example.

The reason for the interest toward the blogs has been studied by most researchers, and it has been revealed that, although not having a prominent impact power in terms of politics, the uniqueness of introduced information and the opportunity of bringing any topic for discussions at world level attracts the users $[10,11]$. Blog creators do not always possess material, moral, social or cultural features. Nevertheless, blogs are capable of gathering people together [11].

Forum is deemed a strong and popular element of social media and one of the first Internet projects. The forums, establishing the basis of Web 2.0 technologies, is an interesting virtual environment of online discussions. In these projects, Internet users gather around a particular subject and interests. The events, conflicts and confrontations are being widely reflected in forums. For this reason, discussions are superseded by hot debates and information confrontation in most forums.

In content sharing project, as most interesting and most-viewed social media projects, the users share images, video and audio files. As an example, Flickr, YouTube, Picasa, Commons and Twitpic can be shown. One of the main problems caused by these projects is associated with copyright rights [12].

Podcast is the creation and translation of audio and video files as radio and television programs on the Internet. The web-sites of Podcast posts operate as a video and audio recording studio by supporting the media-file hosting. Their performance can also be called as video-blog or Internet-radio. These web-sites allow the subscription to media-files. Speeches can be saved as texts in podcasts sometimes. Various software tools exist for using Podcasts. Zune Software, iTunes, Rhythmbox, gPodder and AmaroK are examples.

A microblog is a project comprising the facilities of blog and social media. By generating small-volume information (tweets), microblogs rapidly spread via the Internet network and mobile connection. Twitter is a leader in this field.

New projects are being added to social media fields and this process is constantly proceeding. These projects include social bookmarking (Delicious), opinion and research (Yahoo Answers, Yelp), video sharing (Youtube, Vimeo, Dailymotion), live streaming (Justin.tv), audio and music sharing (last.fm, Grooveshark) and etc.

One of the most frequently used social media projects is Wikipedia virtual encyclopedia [13]. Wikipedia and related projects, created with wiki-technologies, allows to create a web page about any subject, at anytime without quitting the browser, edit pages and upload files, in various formats, on the pages.. Besides content creation, as fully eligible web-programmer on the internet, web-technologies also enable the users to participate in discussions, regardless the occupation and interests, and express their opinion regarding the created and edited content by users, which leads to the establishment of new social relations in the society. Wikipedia has acquired a high rating as one of the web-resources of largest user audience on the Internet, one of the most popular social networks, and the largest knowledge base [4]. The main reason of Wikipedia's popularity is dynamicity and the ability to be updated. Today, a primary information regarding a nation, state, particular event, a popular person and etc. are acquired from Wikipedia encyclopedia. From this point of view, Wikipedia is a primary information source. 
As an example to wiki-projects, open web-sites about virtual encyclopedias, news, tourism, education, and other topics can be shown. Wiki-projects are more suitable for Internet publishing, in comparison with other projects, in terms of the information characteristics. Therefore, the users of wiki-projects do not only acquire encyclopedic information, at the same time, they access to media-files, animated schemes, three-dimensional objects and interactive panoramas posted in web-sites, and become actors of the social network engaged in knowledge generation [8,12].

\section{User content and Creative Commons license}

While studying social media, the notion of "user content" is often encountered. By user content, particular content is considered which pertains to Web 2.0 technologies, created by users, is of particular importance and is voluntarily inserted to open Internet projects from various information carriers. Today, social media is expanded due to user content [14]. User content considers the use of all technologies for content storage and transmission. Podcasts, blogs, wiki-projects, network platforms are considered for image, audio and video upload pertain to those. In some cases, the user content constitutes only some part of web-resource. For example, although in particular websites the main material is posted by administrator, a place is created for user content which leads to more comprehensive and attractive news due to user content. In all cases, the user content is verified by administrators before publishing in order to avoid copyright rights problems.

The expansion of social media, the excessive enlargement of user content, and the rapid continuation of this process have caused the formation of a new generation, trying to use the Internet independently and without any obstacles. The desire of Internet users, which encompasses use of any information for various purposes through free download and uploading, is always topical. However, content authors in traditional web-pages seek to limit the unauthorized use and dissemination of their products by any means. As a result, two sides are formed in the Internet environment, which do not accept each other's attitude: one group does not recognize the copyright rights, while another party does not accept the free content sharing. Creative Commons license has been suggested as an optimal version of the consent between two sides [15].

Creative Commons is a specific license and allows the content author to make amendments in the rights of use of this content. Creative Commons license was proposed by Lawrence Lessig, a law professor of Stanford University, in 2001. This license is a new approach to the management of intellectual property rights, and the purpose is to provide open and legally independent use and dissemination of variety of creative works (book, article, image, music, film and etc.). With those licenses, the authors can apply their authorship rights not fully, but with some concessions, i.e. authors decide on which rights to relinquish or to preserve according to these licenses. For instance, it can be the case that an author does not oppose the dissemination of his work by fans and readers. In another approach, an author can give permission to distribution and use of his work, but its alteration or the commercial use will not be allowed. This approach is called "some rights are reserved". It must be taken into consideration that unlike Creative Commons license, the authorship rights contemplates "all rights are reserved" and in this case, all rights belong to an author.

As a result of social media expansion, millions of artworks are protected and circulated by Creative Commons license. The licenses are used in culture, education, science, government organizations and wide spectrum of Internet projects. The Internet projects, widely using these licenses, are the web sites managed by wiki-technologies: Wikipedia encyclopedia, Wikimapia virtual map [16], Wikitravel virtual travel site [17], and so forth. Various international scientific journals, open data bases, virtual photo galleries, video-projects and web-sites of different content exist, which operate in accordance with Creative Commons license. 


\section{Wiki-environment and the problems of information impact}

Some social network groups aim to impose information impact on society to turn people against the state and national values; to dishonor the history of a particular nation and to damage the economy by wiki-technologies [18]. The crowd that do not use the Internet, social networks and wiki-technologies is a passive majority, and it is unlikely that they will demand something from the state with information impact. The history shows that revolutions, coups, the seizure of power are realized by the socially active minorities exposed to the information impact. Today, in order to prevent the threats against the state, the mechanism of the processes occurring in social media must be studied and understood. In most cases, the distant observations cause the emergence of various assumptions and speculations. However, specific geopolitical results are obtained by information technologies. From this point of view, the decision-making associated with state information security must be carried out against the analysis of events occurring in social media.

In some studies scrutinizing the information impact of social media,, it is indicated that a new media can be deemed neither democratic nor authoritarian. This social project can reflect both attitudes $[18,19]$. This feature also pertains to wiki-environment. In recent years, an opinion is shaped in the society that it is impossible to manage the social media and wiki-environment as its integral part. Firstly, due to that fact that the users are constituted of volunteers and can operate in wiki-projects regardless the place of residence [20,21]. In order to analyze the role of wiki-environment in information impact, the Internet phenomenon must be studied in depth at first stance. The thought that Wikipedia is a truly free project and anyone can edit the desired information does not conform with the reality. The corresponding capabilities of Wikipedia are as large as the threats of the Internet to the security of governments. It must be considered that the Internet is controllable by particular countries and a question rises at this case: who controls Wikipedia? Is Wikipedia established for the purpose of instilling a particular ideology and world view in people or a special form of public relations, a propaganda machine disguised behind the encyclopedic information?

It is well-known that Wikipedia is a strategic Internet resource managed from a special center in Florida state, USA, and it is forming the worldview of the citizens and youth in particular [22,23]. The Wikipedia Fund, managing the Wikipedia project, possesses gigantic supercomputers located in specific strategic points of the world and not available even to the majority of developed states. Servers operate on the basis of Linux operating system. Some part of servers operate as managed data base, based on MySQL, some part as requests cache (Squid), and another part as web-server (Apache). Wiki-servers are machines with super power processing more than 4 billion traffic and defeating any virus and spy programs [23]. The power supply of wiki-servers, high-skilled staff, program and apparatus software require financial resources of millions of dollars and in this case, the fact of possession of wiki-projects by a regular company raises some doubts.

In Wikipedia, the topics are managed by particular groups, protected when needed and the people protesting against the distorted facts are dispelled from Wikipedia [18,26]. The analysis conducted with Wikipedia Scanner program established in California Institute of Technology demonstrated that the majority of articles are created with the participation of the employees of Central Intelligence Agency of USA, Federal Bureau of Investigations, state and education institutions, political parties and information agencies [22]. The principle that "anyone can create and edit the desired information" in Wikipedia is not justified. The permission for any information to be posted in wiki-pages is agreed by the group of specific administrations only. By specific administrators, a group of people "trusted" by Wikipedia Fund are considered, and the members of this group, disguised behind the false names, are engaged in the dissemination of the Western culture and ideology in Wikipedia. 
Wiki technologies are complex and multilevel. It appears as a resource considering the use of any type of content and containing the encyclopedic information at first glance. However, in depth analysis reveales that wiki-projects have large capabilities to cause the formation and alteration of public opinion. The sovereignty of governments and national-moral values, the history and language of nations are infringed and practically, neither Wikipedia members, nor the administration does not bear any legal responsibility for the content in wiki-environment. The number of gathered articles in Wikipedia in English exceeds the articles in other languages millionfold, and are mainly engaged in promulgation of American and English realities, cultural values and prominent persons, and the people eager to work in Wikipedia are firstly offered the translation of these type of articles $[23,26]$. One of the principles of Wikipedia is impartiality. However, beneath the veil of this rule, the youth are offered to victimize the national interests and realities of the nations they belong to Wikipedia rules and unfortunately, the active participants of this virtual project accept these conditions under the veil of impartiality. As a result, the articles about foreign scientists, statesmen and other prominent persons constitute the majority of articles in several languages.

The spam feature is already pertaining to Wikipedia as well. Thus, it is of no coincidence that Wikipedia is at the first page of various search systems. Even if Internet users intend to read the information not from Wikipedia, but from other web-sites, they are forcedly redirected to Wikipedia. The Chinese government which has understood the threat of Wikipedia has established a virtual encyclopedia in 2005, and was able to distract the majority of students from Wikipedia to this encyclopedia. With 11 million articles, this open encyclopedia, called Hudun, is the largest encyclopedia of the world after Wikipedia [24].

The socket puppet technology is largely used in information impact of wiki-environment [25]. Firstly, several virtual accounts and bots are created with this technology and directed towards particular target, and by evaluating a particular event, they introduce it as a public opinion. The user entering wiki-environment is forced to accept the artificially created "public opinion" as a normal case. Actually, this is not the opinion of the majority, but of a group imposing the information impact on a society and managed from a center. Wiki-environment mainly operates with "90-9-1" principle, that is, 90 percent of users are regular readers, 9 percent are the ones making slight changes in content. The main information is created by the group constituting 1 percent [26]. Hence, an important social context and social environment necessary for the solution of a political problem is created by 1 percent of users. It must be taken into consideration that if any political decision or event attempted to be realized by particular groups is not supported by the publicity, its realization is complicated. But, if favorable conditions are created for any political decision or event in a correct way, its realization does not appear to be hard and many adherents are gained.

\section{Resolution of problems}

The activity of users in wiki-environment can appear in different format: cooperation, competition, integration and confrontation. The analysis of each position facilitates the forecasting the prospective development of the events in wiki-environment. It is to be considered that, as in all social networks, the main part of users in wiki-environment are constituted by the active part of the society on the Internet and they are mainly intellectuals, politicians, media workers and other highly skilled experts engaged in intellectual labor. They are socially active persons with the Internet access and the skills to work with information, and they are specified as main targets of information impact. Therefore, the subject of encyclopedic articles reflects the purpose of users editing those articles $[20,23,26]$. This, firstly, impacts the volume, topicality and the accuracy of the information in an article, and creates severe distinctions among Wikipedia articles.

Today, the social media is a tool maintaining related activity of the political movement in the world. Social media is a tool stimulating the consolidation and expansion of the civil society. 
This approach is deemed as "external environment" in several literature sources [18]. Wikitechnologies, as one of the instruments of social media, are fundamentally changing the mutual relations of a citizen and the state. New tendencies associated with wiki-environment create big opportunities for the impact of a particular country on the social life of other country and the information environment of its citizens. For this reason, several advanced countries are using wikitechnologies for political and economic purposes by studying the capabilities of those technologies. But it must be determined how the information needs of citizens of separate countries are met and which sources of information impact are used. These are the primary issues posed in relation to the security maintenance of information space of every country. It must be considered that information needs of citizens of separate countries can comply not only with the interests of their country, but of others. The support of wiki-projects by Google gigantic search server and the suggestion of information contained in Wikipedia encyclopedia, as the first suggestion in any information search, proves the prominent role of the Wikipedia in information need of citizens. Main tendencies providing the information impact of wiki-environment are shown below.

- rapid increase in content volume in wiki-environment;

- enhancement of opportunities for interactive use of wiki-content;

- escalation of information confrontations in wiki-environment;

- commercial character of wiki-environment in recent years;

- technical and economic convergence of traditional encyclopedias and Wikipedia;

- globalization of wiki-environment.

On the other hand, the fight against Web 2.0 and wiki-technologies is a hard task in terms of information security. For instance, the environment of adherent wiki-users is necessary for the revolution in web-environment, and if this environment is absent, it must be created artificially. The French philosopher Gilles Deleuze, who describes the features and the structure of the network, mentions that a special impact network must be created in a rival area in order to fight against the social network. Hence, after creating the environment, the realization of destructive scenario in such environment is possible; the operation principle of such gigantic information base such as Wikipedia and the behaviors of active groups prove the need for accurate study of the network [27].

Wiki-environment is a social network created by USA, and it operates in 300 languages. If a group opposing the state is formed in this environment and information war is pursued, a new network serving to the government interests must be created, as suggested by G. Deleuze, and the information must be posted in that network, which is capable to supersede the content created by the rival party. It is to be mentioned that the target attracting the attention of network users is limited. An individual reads and comprehends as much information as physically achievable. So, the exclusion of destructive content is possible with the creation of alternative content, which can attract the users.

The approaches used in the analysis of social networks, operating in wiki-environment, can be generally used in the analysis of social media. The solution of the following issues is important in the analysis of different impact methods of Wikipedia on political spheres and economy:

- Technical and software tools used for the information impact by Wikipedia must be specified;

- The negative consequences of the impact of Wikipedia on citizen behavior must be determined;

- All projects operating in wiki-environment at present must be analyzed; new projects to be created and their role in information impact must be specified.

In order to study the information impact in wiki-environment, its social network must be analyzed. The monitoring and evaluation of main indicators must be carried out. The monitoring in network is carried out with specification of key worlds relevant to the studied object field. All 
information exchanges are tracked and the data is organized for next analysis in this process. During the evaluation of indicators, more important indicators are specified. Moreover, the main features of wiki-environment must be considered and the following directions must be specified:

- capacity of wiki-environment;

- links among the actors of network;

- philosophy, nature and the power of wiki-environment for determining the functionality of the latter;

- problems and the causes of those.

\section{Conclusion}

As a result of the research, it has been revealed that social media is not only an information source, but also one of the tools of information impact. The social media is a tool for discussions in virtual space for the creation of virtual base of different types of files storage, and cooperation with other Internet users due to the ability to access instantly to desired information on the Internet. Social media is a set of projects that facilitate the development of professional critical thinking and the independent analysis by people that expands day by day and becomes popular.

Wiki-environment as one of the main tools of social media is a large knowledge source and a social network today. Like in traditional social networks, the information in wikienvironment is realized not directly, but indirectly. The main features of wiki-environment are the multi-media character, operativity, interactivity, the ability of rapid adaptation against changes, parallelism in communication and the ability of retranslation of information. Wikiprojects are used for the illumination of a particular event or a prominent issue not only by usual citizens, but also by experts attempting to evaluate a specific event, and for different radical groups and organizations trying to manage the minds of citizens, mobilize and engage people in protest actions at the same time.

The investigations showed that the popularity of Wikipedia and the continuous increase in number of articles posted cannot be considered as a positive case as such; this also implies that wiki-environment plays a prominent role in information impact and proves its dangerousness. Hence, the wiki-environment is a tool granting the democracy and the openness in a society as well as a malicious instrument facilitating the disturbance of political stability. The analysis of information impact in wiki-environment is one of the significant tasks for the maintenance of security of the government information space. For this reason, the states aspiring to maintain their information space security must be capable to control the wiki-environment.

\section{References}

1. Alguliev R.M. Mahmudov R.Sh. The essence, features of Internet and some views on its impact opportunities // Problems of the Information society, 2012, №1, pp. 41-51.

2. http://www.sosialmedia.net/?page_id=7

3. Alguliev R.M., Valehov J.F., Mahmudov R.Sh. Some aspects of the formation of Internetjournalism. Express-information. The Information society series, Baku, "Information Technologies" press, 2008, 32 p.

4. Alguliev R.M., Alakbarova I.Y., Kasumova R.T. The collective knowledge in Internet // Proceedings of sixth international scientific-technical conference "Internet-EducationScience-2008", Vinnytsia, 7-11 October, 2008, pp. 5-7.

5. Rozina I.N. Communications 2.0: educational and social dimensions, limitations and opportunities // Educational technologies and the society, 2010, vol.13, №2, http://www.ifets.ieee.org/russian/depository/v13_i2/html/6.htm

6. Alakbarova I.Y. The analysis of some information war technologies carried out in Wiki environment // Problems of the Information society, 2011, №2(4), pp. 18-28. 
7. Benkler Y. The Wealth of Networks: How Social Production Transforms Markets and Freedom, Yale University Press, 2006, 527 p.

8. Alakbarova I.Y. On some approaches to the analysis of information impact of users in social networks // The Information society, M., 2012, №3, pp. 31-38.

9. Mayfield A. What Is Social Media? http://www.repromax.com/docs/113/854427515.pdf

10. Farrell H., Drezner D. W. The power and politics of blogs // Springer Science and Business Media, 2008, vol. 134, no. 2, pp. 15-30.

11. Perlmutter D. Blogwars. Oxford University Press, 2008, 272 p.

12. Christensen H. Social media, big data and the next generation of e-health interventions, https://www.psychology.org.au/Content.aspx?ID=5848

13. http://wikipedia.org

14. Pavlik J. Converging Media. Oxford University Press, 2014, 140 p.

15. http://www.creativecommons.ru/licenses

16. http://www.wikimapia.org

17. http://www.wikitravel.org/en/Main_Page

18. Baluev D.G. The political role of social media as a field of scientific research // Educational technologies and society. 2013, vol.16, № 2, pp. 604-616.

19. Nye J.S. The Powers to Lead. Oxford University Press, 2008, 240 p.

20. Halavais A., Lackaff D. An Analysis of Topical Coverage of Wikipedia // Computer-Mediated Communication, 2008, vol. 13, no. 2, pp. 429-440.

21. Alakbarova I.Y. The analysis of the socio-demographic portrait of wiki-environment // Problems of the Information Society, Baku, 2012, № 1, pp. 21-28.

22. Garifullin R.R. Wikipedia: psychology of virtual war, http://www.psyfactor.org/lib/garifullin11.htm

23. Alguliev R.M., Aliguliev R.M., Alakbarova I.Y. Wikimetric studies: the current state and perspectives // Telecommunications, 2014, №5, pp. 15-31.

24. http://www.hudong.com

25. https://en.wikipedia.org/wiki/Wikipedia:Sock_puppetry

26. Sumi R., Yasseri T., Rung A., Kornai A., Kertész J. Edit wars in Wikipedia / Proceedings of the IEEE Third International Conference on Social Computing, 9-11 Oct. 2011, pp. 724-727.

27. Awan A.N. Virtual Jihadist media: Function, legitimacy, and radicalizing efficacy, European Journal of Cultural Studies, 2007, vol. 10, no. 3, pp. 389-408. 